\title{
Conceptual Design And Hydrodynamic Research On Unmanned Aquatic Vehicle
}

\author{
V Praveen Kumar, S Kishor Kumar, K R Sankaresh Pandian, E Ashraf, K Thanga Tamil Selvan, \\ Vijayanandh R
}

\begin{abstract}
Autonomous Underwater Vehicles (AUVs) are one of the significant types of aircraft, which are traveled in submarine by the pre-programmed control process. At the present time $A U V$ is being projected for many serious applications together with fault exposure on the dam, tragedy monitoring, naval supervision, and fisheries safety. Interest in AUVs for ocean investigation and mapping, inspection, and forecasting have emerged progressively, in which the AUVs design methods are implemented in submarine are regularly multi-rotor arrangement AUVs. In submerged applications, multi-rotor based AUVs are low proficient in terms maneuvering practicability, existence, as a result, the designer must make available an $A U V$, which has the high lifetime, high efficient in devise, more secure on-flight and low continuation cost in order to endure at the decisive environment. In this article proposed a unique AUV, called Unmanned Aquatic Vehicle (UAV) inspired by the approach of flying fish, this can able to maneuver in underwater with high competence, in which estimation of resourceful have been derived based on theoretical design, manipulation realization process, communication, a existence of a UAV. Advanced numerical imitation have the ability to solve decisive problem so in this paper used CFD, in which, the ordered grid of the computational models for dissimilar types of UAVs is generated by Ansys ICEM CFD 16.2. This discretized model represents as the imitation of $U A V$, which is used to forecast the flow performance of the orientation module, and examine the hydrodynamic belongings on its sub-components. In this article, ANSYS-FLUENT 16.2 software is used as arithmetical solver tool, which is a influential tool for solving troubles concerning fluid mechanics. Results of the velocity, pressure allocation, and drag coefficient are analyzed. The characteristics of the drag, lift, pitching moment partial by the distance to the sea underneath and the attack angle are studied, which provided the path for UAV intend optimization.
\end{abstract}

\section{INTRODUCTION}

\subsection{Aim}

The main aim of this work is to detect the fish and its count in the Tamil Nadu Naval region in order to avoid the fishers' international border crossing with the help of Unmanned Aquatic Vehicle.

\subsection{Unmanned Aquatic Vehicle (UAV)}

Revised Manuscript Received on September 10, 2019.

V Praveen Kumar, BE Student, Aeronautical Engineering, Kumaraguru College of Technology, Coimbatore, Tamilnadu, India. (Email: praveenpk1801@gmail.com)

S Kishor Kumar, BE Student, Aeronautical Engineering, Kumaraguru College of Technology, Coimbatore, Tamilnadu, India.

K R Sankaresh Pandian, BE Student, Aeronautical Engineering, Kumaraguru College of Technology, Coimbatore, Tamilnadu, India

E Ashraf, BE Student, Aeronautical Engineering, Kumaraguru College of Technology, Coimbatore, Tamilnadu, India.

K Thanga Tamil Selvan, BE Student, Aeronautical Engineering, Kumaraguru College of Technology, Coimbatore, Tamilnadu, India.

Vijayanandh R, Assistant Professor, Aeronautical Engineering, Kumaraguru College of Technology, Coimbatore, Tamilnadu, India.

(Email: vijayanandh.raja@gmail.com)
One of the emerging techniques in the Aerospace Industry is Unmanned Aircraft (UA), which was constructed with the help of advanced electronics equipment. Initially the UAs were implemented in the aerial environments only but due to the advancements of electronics, the implementation is extended ground and aquatic environments too. The UAV is a kind of UA, which can able to operate perfectly in the underwater environments. Comparatively aquatic conditions have more capability to provide disturbances such as high dense working conditions, nature obstacle, large fishes, etc so the thinking about UAV is emerging day by day in order to complete assigned mission with high lifetime. Fluid resistance and hydrodynamic coefficients are the primary aspects of the development and research of UAV [1].

\subsection{Summary on Conceptual Design of UAV}

Generally implemented UAVs are commonly comes under multi-rotor configuration category with low performance. The UAV based on multi-rotor configurations has low efficiency in the perspective of low speed attainment and high opposing force. Also multi-rotor Aquatic Vehicles are unfit for high speed applications so alternation is mandatory in underwater mission. From these observations, some functional requirements are proposed and serve as guidelines for the design of a new type of UAV which need to have certain characteristics such as it can float stably on water, it need to be Fixed wing for long endurance, better control surface to execute perfect maneuvering. To complete the mission of this work, flying fish design is supported towards the successful design of the UAV. It is an exceptional marine flying vertebrate showing successful gliding capabilities in the air [2]. The flying fish glides over a total distance of as much as $400 \mathrm{~m}$ in $30 \mathrm{~s}$ by a successive sequence of taxiing and flight, and its maximum flight speed is in the region of 10 to $20 \mathrm{~ms}^{-1}$.

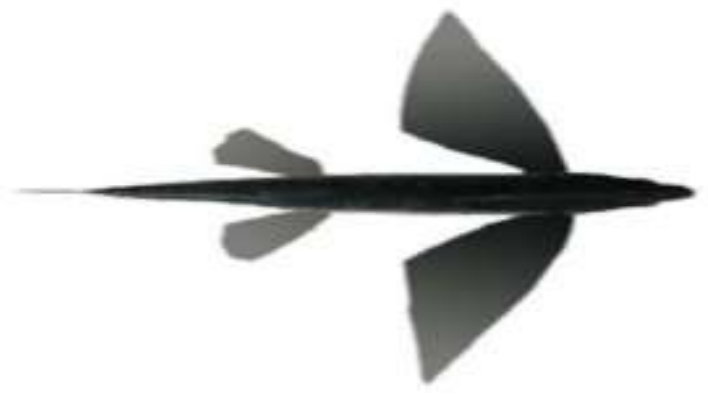

Figure 1. Flying Fish

Figure 1 shows the simple pictorial representation of Flying Fish for understanding of basic structure of Navel vehicle 


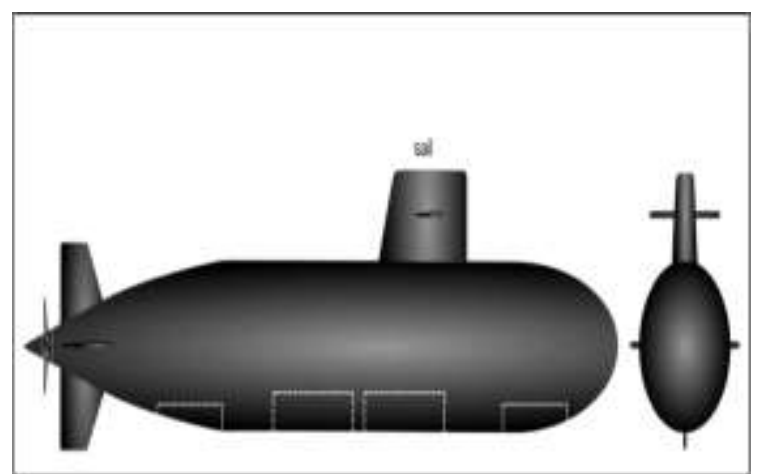

Figure 2. Typical view of submarine

Figure 2 shows the Shape of Submarine in typical views. From the structure of flying fish body, which resembles the hull of a submarine.

\subsection{Summary on Estimation methodology}

The accurate and deep research on the hydrodynamic effect of UAV, which undergoes inside the water, has a great significance for its maneuverability. Research and development of this class of vehicles have grown, due to the excellent characteristics of the UAVs to operate in critical situations. Therefore, this study aims to analyze hydrodynamic flow behavior over different geometry configurations of a UAV, in order to obtain test geometry that generates lower drag force, which reduces the energy consumption of the vehicle, thereby increasing their autonomy during operation [3]. The design of such a vehicle is demanding because it implies important propulsive and structural plan trade-offs for process in submarine, in which the demanding to be rise above with the aid of complex engineering analysis such as CFD replication, strong academic formulae, etc. inference of hydrodynamic coefficients were effectively analyzed by $\mathrm{H}$. Zhang and $\mathrm{Y}$. $\mathrm{Xu}$ [14] with the help of CFD software Fluent. Ettore A. de Barros [13] completed the comparative study by using CFD software Fluent, in which he confirmed that Fluent has full ability so resolve hydrodynamic applicable troubles so in this paper intended to use Ansys Fluent as a main tool. The struggle and the hydrodynamic coefficients are primary parameters need to be effectively estimated by the computational tool. And then the forces acting on the UAV with respect to its depth is plays a vital role in the design optimization of UAV.

\section{CONCEPTUAL DESIGN OF UNMANNED AQUATIC VEHICLE}

\subsection{Selection of HULL}

Minimum drag is one of the key selective parameters involved in the underwater vehicle, which could be achieved in submarine with the help of the ideal streamlined shape with a parabolic bow and an elliptical stern. The usable volume within the hull was insufficient, as the radius of the hull saw a steep decrease from just aft and forward of the mid-ship region [5].

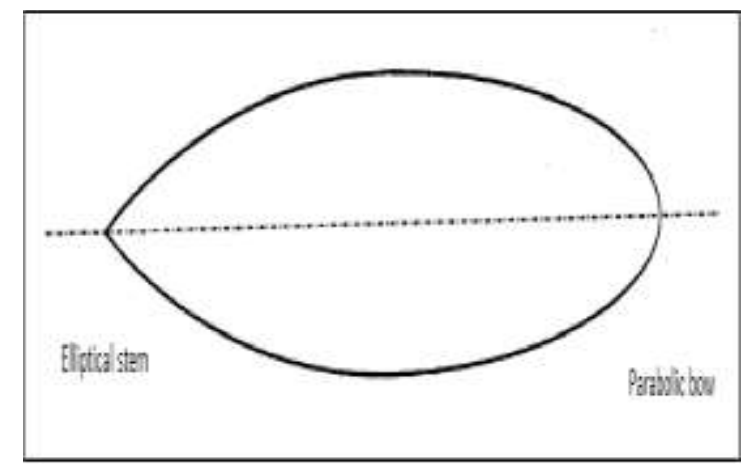

Figure 3. Initial Shape of Hull

Figure 3 shows the ideal Shape of the hull in submarine with parabolic shape at the rear end. From the region, the nose part is further blended to get Modern submarine "Hull form with the cylindrical mid-body", which resembles as

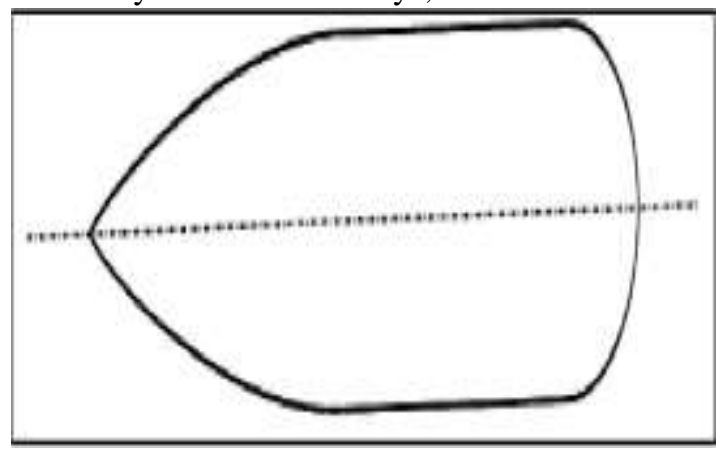

Figure 4 shape of hull

Figure 4 shows the Submarine hull form with cylindrical midbody and eliptical shape at the end [6].

\subsection{Design module}

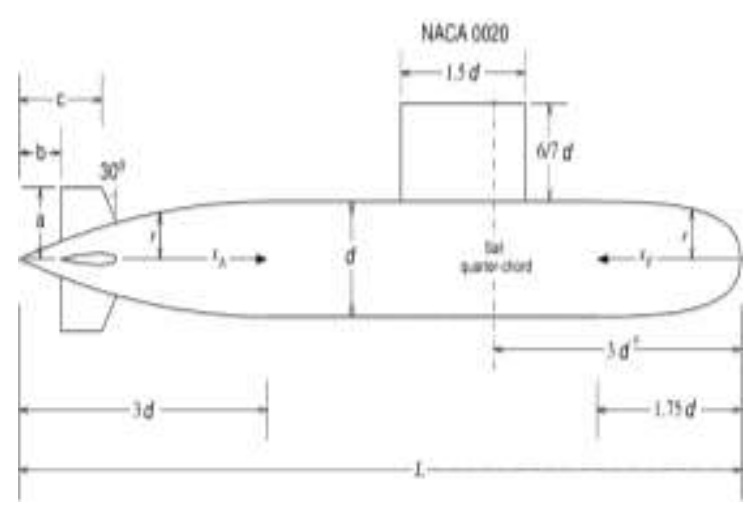

Figure 5. Fundamental Geometry [7]

Figure 5 shows the basic geometry of Naval Vehicle which is used to construct the $3 \mathrm{D}$ structure. From the literature work, the following design parameters are finalized for this project where the length of the vehicle is $120 \mathrm{~cm}(1.2 \mathrm{~m})$. By subsuiting length value in this relation $\mathrm{L}=8.75 \mathrm{~d}$, we got diameter of vehicle as $13.72 \mathrm{~cm}$ where the Tail appendages of four identical airfoil which is of NACA 0015 series. The length of the control surface(a) is given as $0.625 \mathrm{~d}$ and distance of control surface(b) from end is $0.5 \mathrm{~d}$ whereas $\mathrm{c}$ is $1.0 \mathrm{~d}$; 


\subsection{Control Surface}

Both rudder \& elevator are used in our Aquatic Unmanned Vehicle. Other control surfaces like wings, aileron, flaps are neglected cause no rolling action was performed. Pitching and yawing is achieved by rudder and elevator. Elevator \& rudder are identical to each other [8].

\subsubsection{Selection of Airfoil}

NACA 0015 is commonly used hydrofoil for hydraulic machinery, here the control surfaces are built by using NACA 0015. It's a symmetric airfoil and its ultimate objective is to keep the UAV stable in the water. The use of CFD technology greatly reduces the overall investment and efforts for airfoil design.

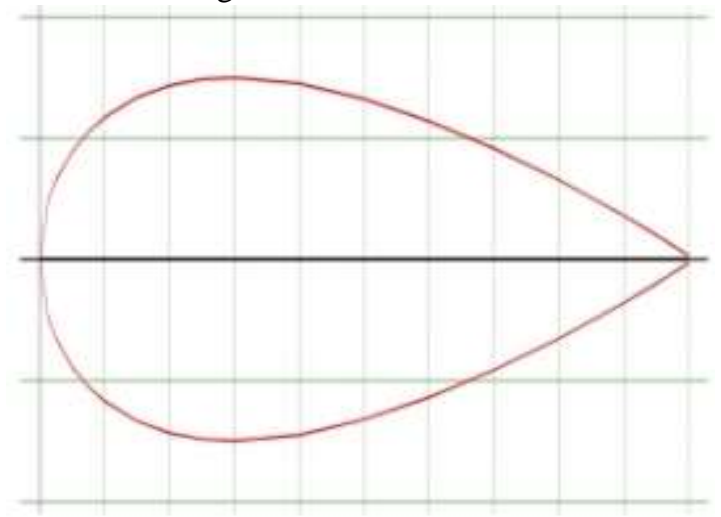

Figure 6. NACA 0015

Figure 6 shows Airfoil NACA 0015 that is used for construction of control surface. The distance between the leading \& trailing edge is $6.86 \mathrm{~cm}$ and the airfoil is extruded to the pad length of $8.575 \mathrm{~cm}$ on both sides. The total length of the elevator is $17.15 \mathrm{~cm}$. Identical values are fixed to rudder respectively [8].

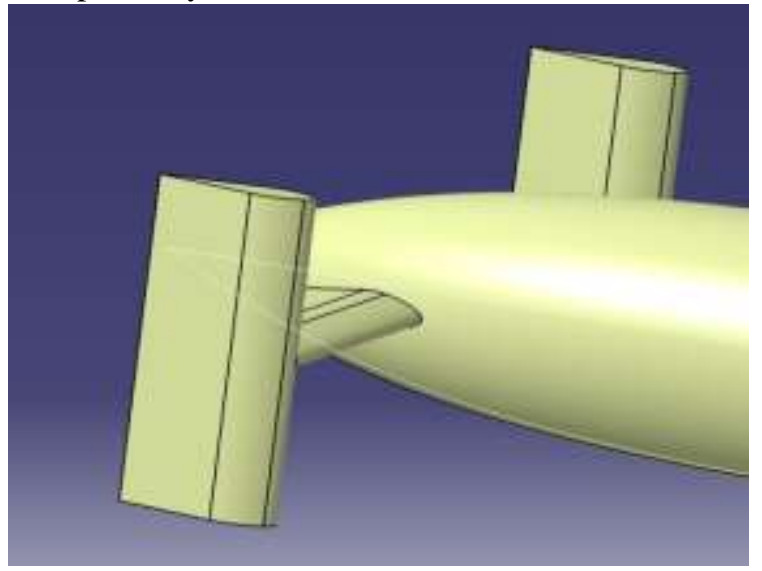

Figure 7. Control surface

Figure 7 shows the 3D representation of Control surface (4 identical) which give maneuvering to the vehicle [9].

\subsection{Landing gear}

Landing gear is used to prevent the UAV's collusion with the ground which causes a structural change. Its placed in the center part of the fuselage. $10 \%$ of the fuselage diameter is considered as the thickness of the landing gear. The diameter of the fuselage is $13.72 \mathrm{~cm}$ hence the diameter of the landing gear is $1.372 \mathrm{~cm}$. Length of the landing gear is double of a diameter, so length is taken as $27.42 \mathrm{~cm} \mathrm{[10].}$

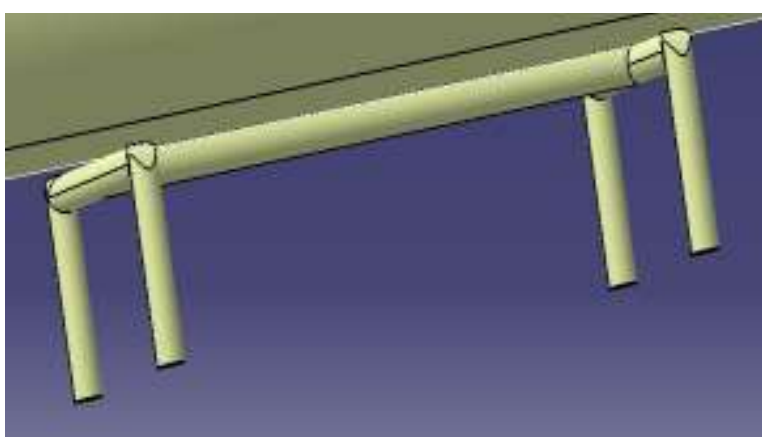

Figure 8 Typical View of Landing Gear

Figure 8 shows the different view of the landing gear that is used for vehicle

\subsection{Sketch module}

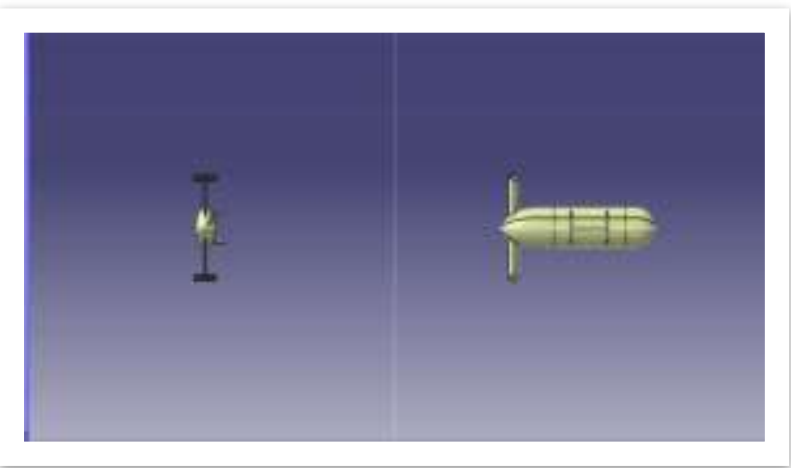

Figure 9. Typical view

Figure 9 shows the Top View of navel UAV

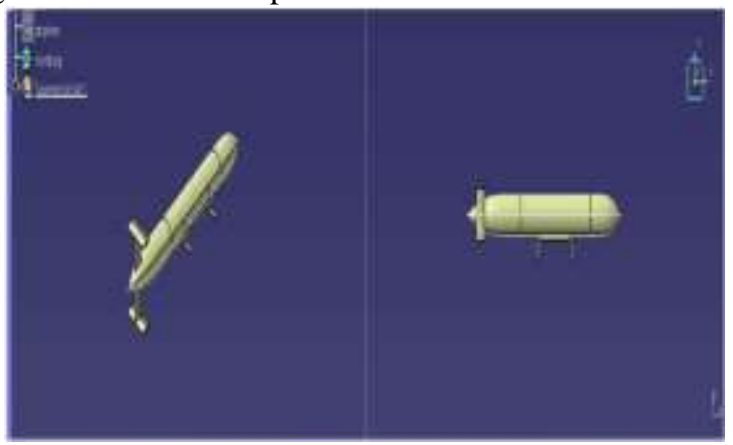

Figure 10. Typical view

Figure10 shows the Front view and the Side View of Navel UAV

\section{NUMERICAL SIMULATION \& RESULTS}

\subsection{Discretization}

Initially, the mesh is generated, in which we assign names to some of the edges to make creating boundary conditions for the mesh easier. Select two vertical edges on the right side of the mesh and select create named section. Name the edges "OUTLET". Select the edges in the correspondent to the inlet of the flow\& select, create the named section and name the selection as "INLET" [11].

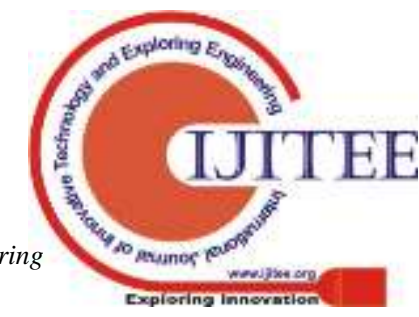




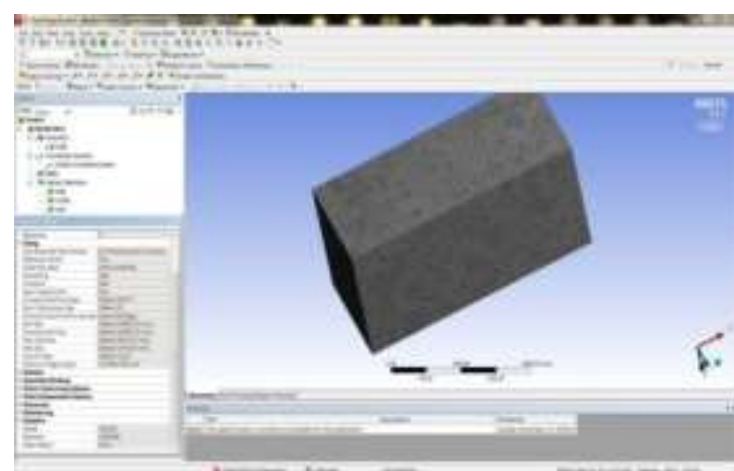

Figure 11. Discretized Model

Figure11 shows the Discretized Model of Navel UAV with a distance of $2 \mathrm{~m}$ along both the axis

\subsection{CFD Simulation}

\subsubsection{General}

Steady and the Pressure based is chosen cause our working fluid is water (incompressible fluid) with constant density is applicable for a wide range of flow regimes from low-speed incompressible flow to high-speed compressible

\subsubsection{Models}

\section{Case 1:}

Using the boundary conditions in the K-Omega methods and used pressure-based which is applicable for the working in the fluid with constant density and followed the overall procedure that are discussed in the later part. The result gets diverged.

\section{Case 2:}

Then only used standard K-epsilon most suitable for our case. Turn off the energy equation for neglecting changes in temperature in water fluid.

\subsubsection{Materials:}

The material that is used for analyzing is

seawater with the constant density of $1025 \mathrm{~kg} / \mathrm{m}^{3}$ and the fluid name is $\left(\mathrm{h}_{2} \mathrm{O}<\mathrm{I}>\right)$ Water liquid [13].

\subsubsection{Cell zone condition:}

The Zone used for this condition is Fluid and the name of material is Water liquid where the Operating pressure is of 106352.6 Pa.

\subsubsection{Case: 1-Boundary Conditions:}

In ANSYS fluent analysis, after discretizing the model, The Inlet Type used for this condition is Velocity inlet whereas Outlet type is Outflow. The Velocity is taken as 15 $\mathrm{m} / \mathrm{s}$ [14]. flow [12].

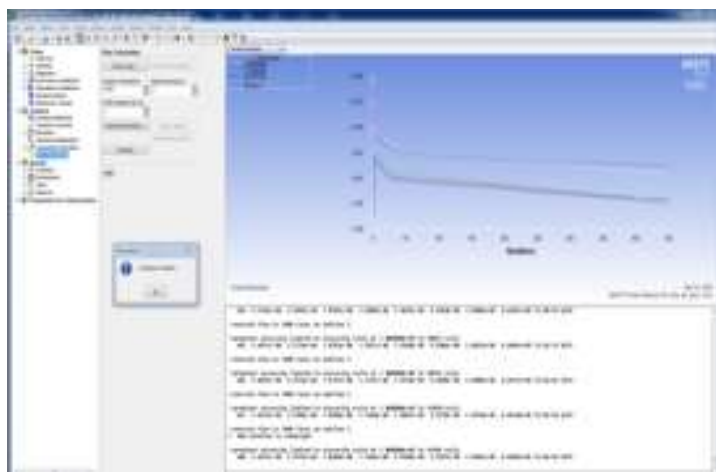

Figure 12. Residual Plot

Figure 12 shows the Residual plot for the pressure, velocity, and turbulence at six different equation.

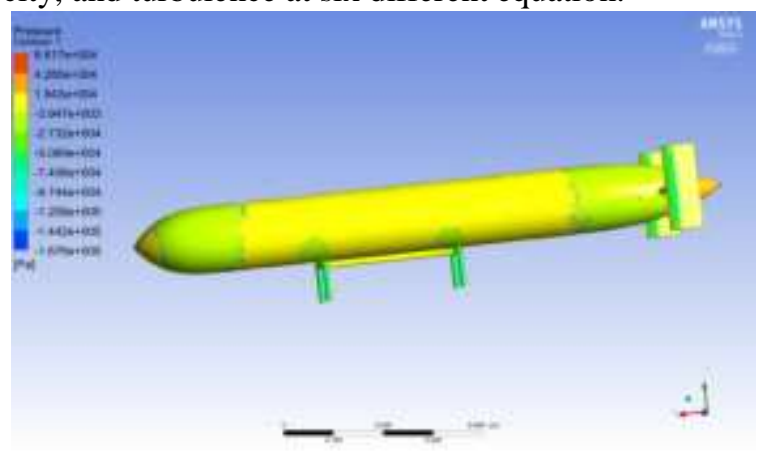

Figure 13 Pressure Contour

Figure 13 shows the Variation of Pressure over the Navel Vehicle.

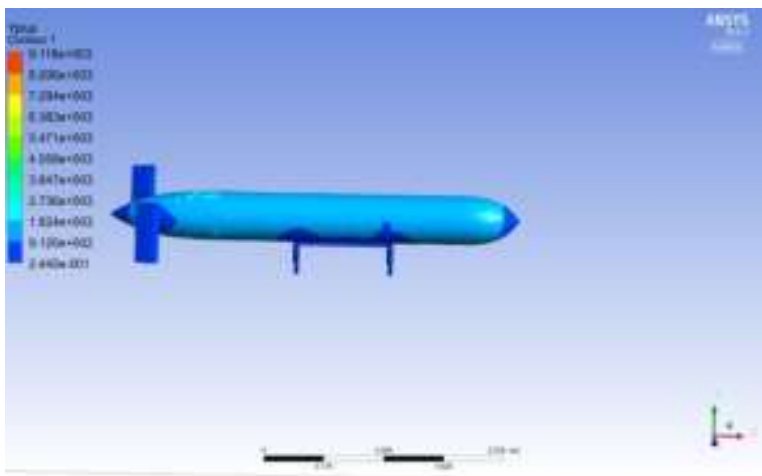

Figure 14 Y-Plus value

Figure 14 shows the Y plus (most prominent parameter) for the given velocity.

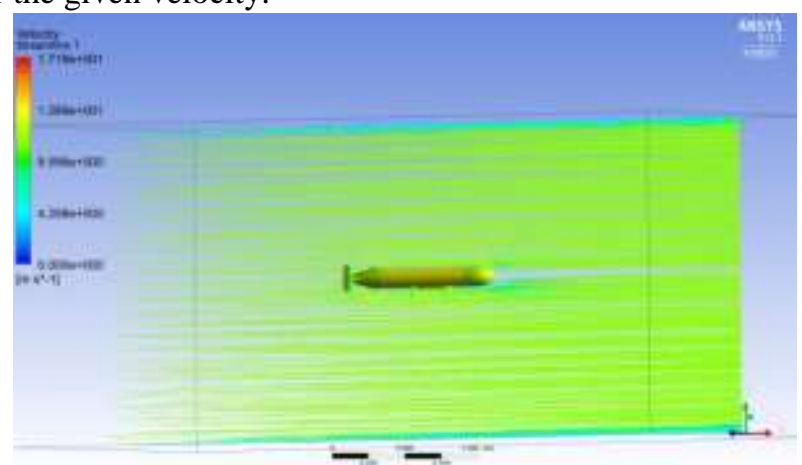

Figure 15 Streamline velocity 
Figure 15 shows the Velocity Streamline of Navel UAV.

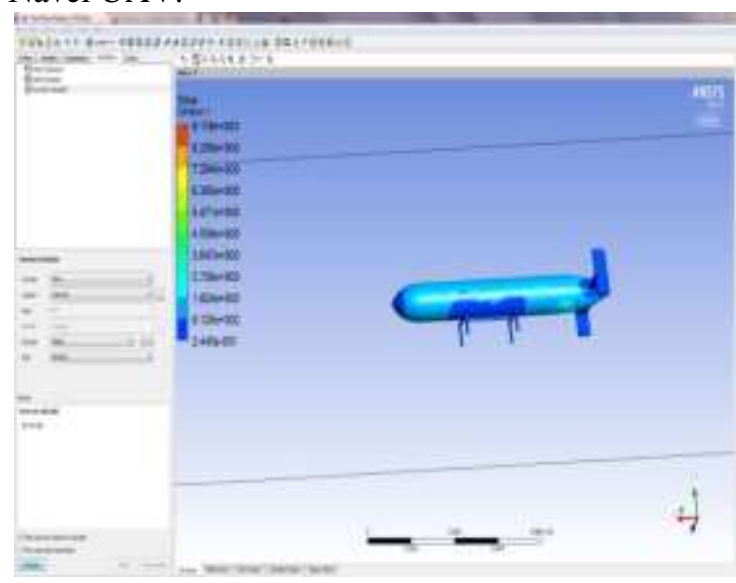

Figure 16 Drag Fore

Figure 16 shows how the Drag force varied over the Navel Vehicle. For given boundary condition, the drag value is estimated as $1101.1 \mathrm{~N}$.

\section{Case: 2 - Boundary Conditions:}

For this case, the Inlet and outlet Type is similar to the previous case, where the velocity is taken as $10 \mathrm{~m} / \mathrm{s}$.

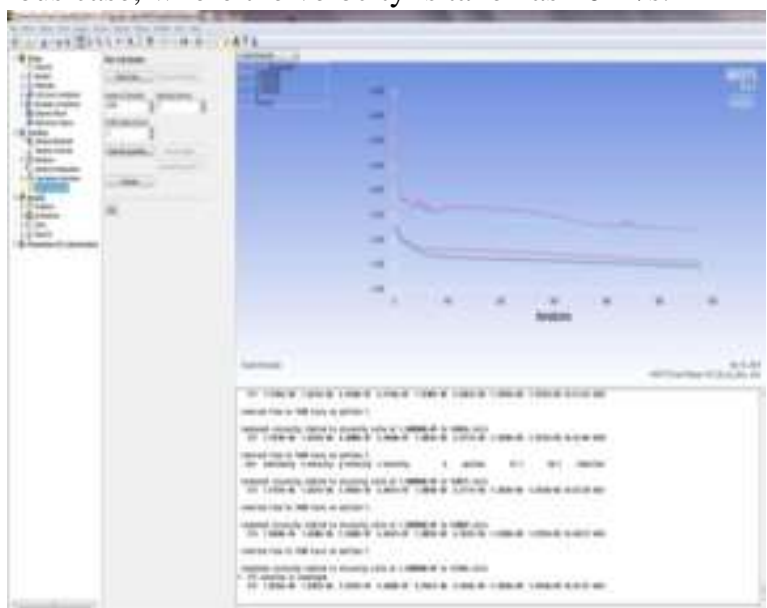

Figure 17. Residual plot

Figure 17 shows the Residual plot for the pressure, velocity and turbulence at six different equations for different velocity.

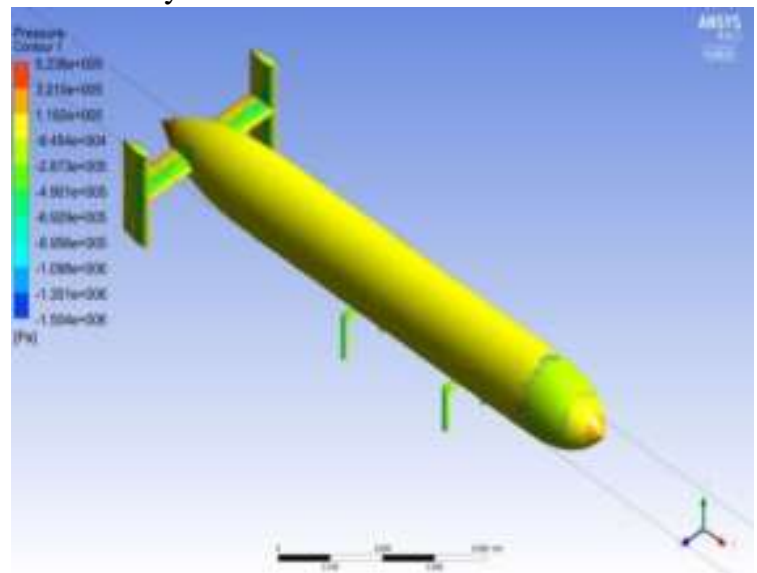

Figure 18 Pressure contour

Figure 18 shows the Pressure variation over the Naval UAV

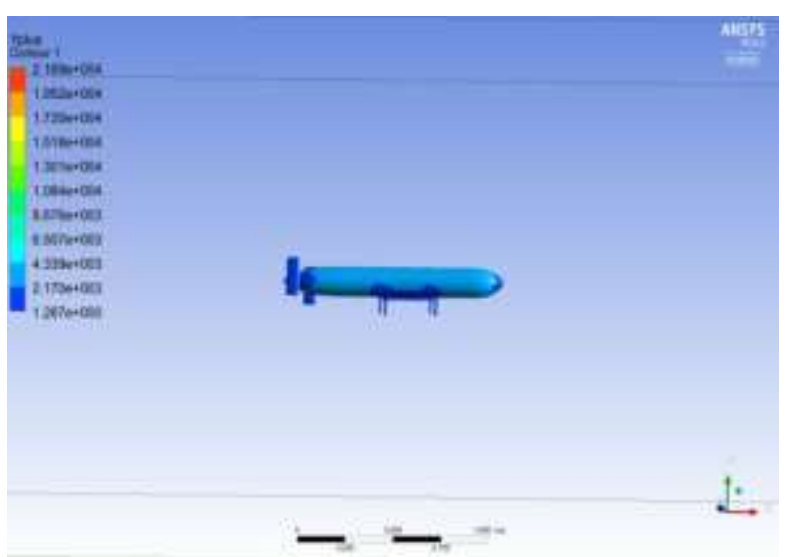

Figure 19 Y-Plus value

Figure 19 shows the Y Plus value where the wall function being judged

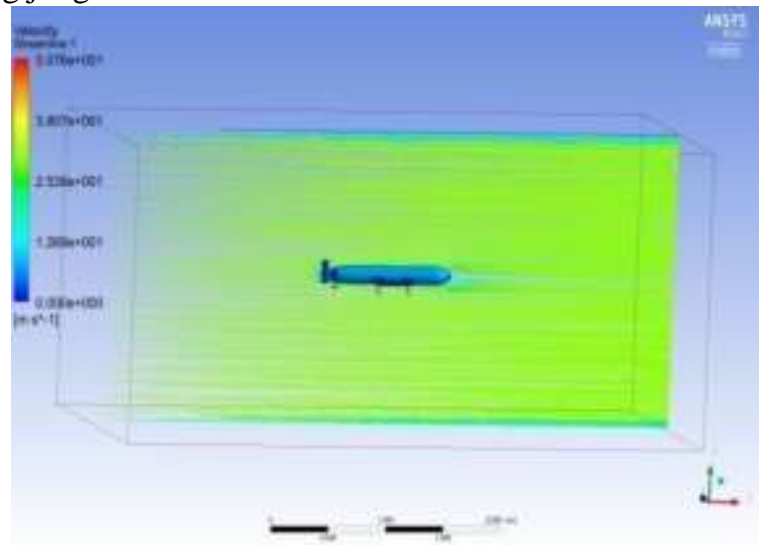

Figure 20 Velocity streamline

Figure 20 shows how flow act over the UAV for given velocity (Velocity Streamline)

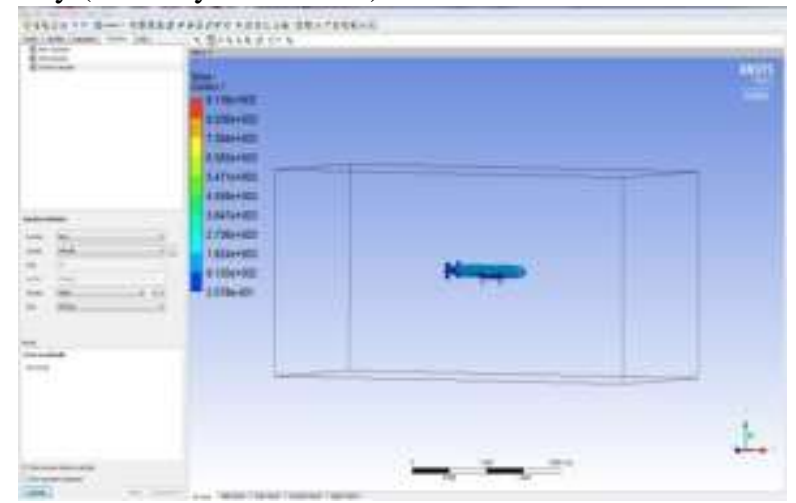

Figure 21. Drag force

Figure 21 show how drags force acting over a different part of Vehicle. For similar boundary condition, but for velocity of $10 \mathrm{~m} / \mathrm{s}$ the maximum Drag Force value is estimated as $597.335 \mathrm{~N}$.

\section{Case: 3- Boundary Conditions:}

Here both Inlet and outlet Type are similar to first case however the velocity is taken as $5 \mathrm{~m} / \mathrm{s}$.

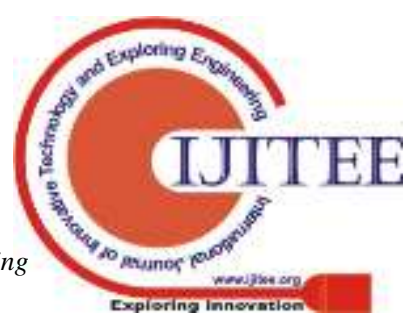




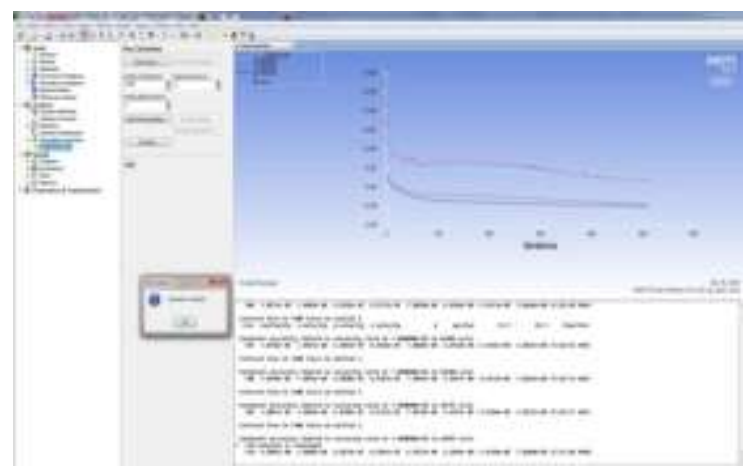

Figure 22. Residual plot

Figure 22 shows the Residual plot for the pressure, velocity and turbulence at six different equations for the final case

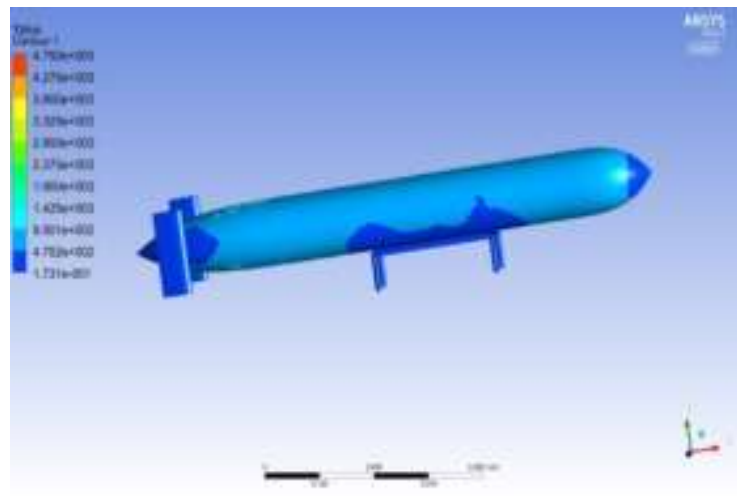

Figure 23. Y-Plus

Figure 23 shows the Y Plus of the vehicle for final case

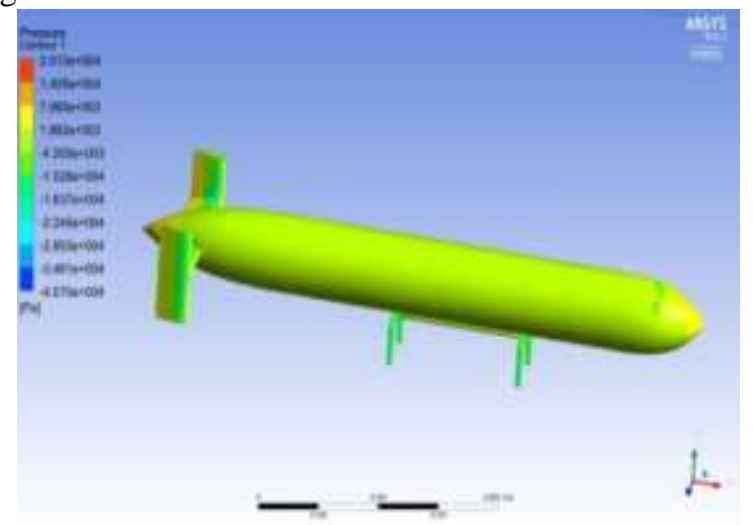

Figure 24. Pressure Contour

Figure 24 shows how pressure varied over the navel vehicle

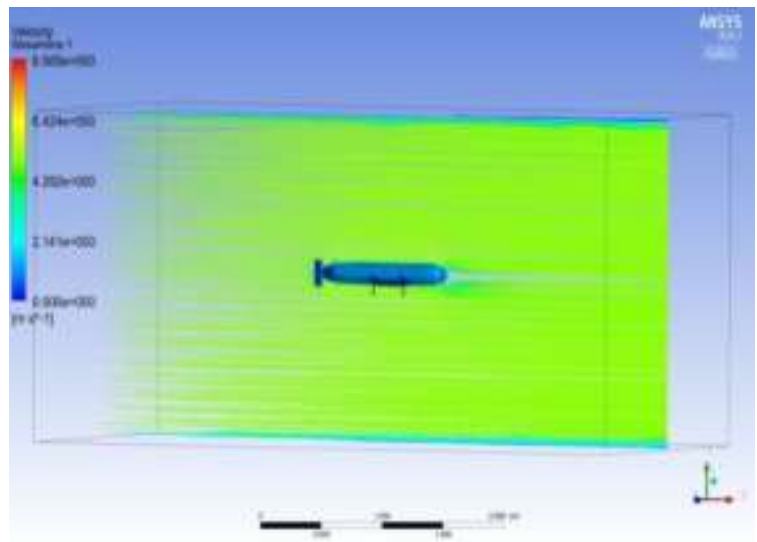

Figure 25. Velocity streamline
Figure 25 shows how flow acts over the UAV for given velocity (Velocity Streamline) for the final case

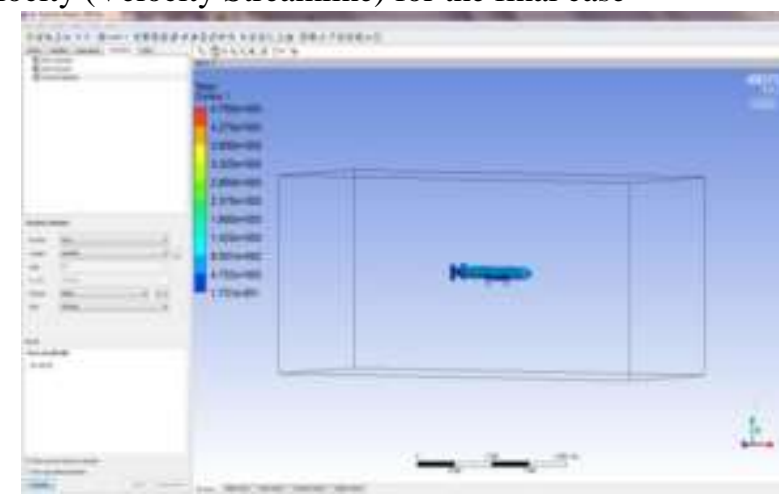

Figure 26. Drag Force

Figure 26 shows drag Force acting over the Navel vehicle for final case. For the similar boundary condition, by only varying velocity as $5 \mathrm{~m} / \mathrm{s}$, the maximum Drag Force is estimated as $152.49 \mathrm{~N}$

\section{CONCLUSION}

This work presents the modeling, design and numerical simulation of a fixed-wing configured aquatic UAV. The fundamental idea about UAV's designs emerged from the flying fish and the remaining construction was constructed with the help of existing submarine design parameters to design high forward speed UAV for detecting and count the fishes. The maximum speed of the fish is around $30 \mathrm{~m} / \mathrm{s}$ and the average speed is $25 \mathrm{~m} / \mathrm{s}$ so this work forced towards the hydrodynamic analysis on the modeled UAV with the help of Ansys Fluent 16.2. The important considerations of this hydrodynamic analysis are drag force and fluid properties variation along its entire object. From the field work, the design parameters and boundary conditions are concluded. Reference component of this work is modeled with the help of CATIA. From the simulation, by comparing finalized both the turbulence methods, hydrodynamic results are converged only in the $\mathrm{k}$-epsilon method. With the help of standard boundary conditions, the simulation is completed for the different velocity of $5,10,15 \mathrm{~m} / \mathrm{s}$ in which the drag velocity of $152.49 \mathrm{~N}, 597.335 \mathrm{~N}, 1101.1 \mathrm{~N}$ are estimated respectively. At the $15 \mathrm{~m} / \mathrm{s}$ input conditions, the drag force has a huge impact on UAV, so the design needs to be optimized to achieve $30 \mathrm{~m} / \mathrm{s}$ without trouble.

\section{REFERENCES}

1. Vijayanandh R et al., Material Optimization of High Speed Micro Aerial Vehicle using FSI Simulation, Procedia Computer Science, Volume Number 133, 2018, pp 2-9.

2. Vijayanandh R., Design Optimization of Advanced Multirotor Unmanned Aircraft System Using FSI, Book Title " Innovative Design, Analysis and Development Practices in Aerospace and Automotive Engineering (I-DAD 2018)", Springer Series Title - Lecture Notes in Mechanical Engineering, eBook ISBN - 978-981-132718-6, Chapter number 28, DOI 10.1007/978-981-132718-6. 
3. Barlow, J. B., Guterres, R. and Razenbach, R. (2001). Experimental parametric study of rectangular bodies with radiused edges in ground effect. J. Wind Eng. Ind. Aerodyn.

4. Tucker, V. A. and Parrott, G. C. (1970). Aerodynamics of gliding flight in a falcon and other birds. J. Exp. Biol.

5. R. Cory and R. Tedrake, "Experiments in fixed-wing UAV perching," in Proceedings of the AIAA Guidance, Navigation, and Control Conference. AIAA Reston, VA, 2008, pp. 1-12.

6. G. Xu, Y. Zhang, S. Ji, Y. Cheng, and Y. Tian, "Research on computer vision-based for UAV autonomous landing on a ship," Pattern Recognition Letters, vol. 30, no. 6, pp. 600-605, 2009.

7. Bettle, M.C., Gerber, A.G., Watt, G.D., Using Reduced Hydrodynamic Models to Accelerate the PredictorCorrector Convergence of Implicit 6-DOF URANS Submarine Manoeuvring Simulations, Computers \& Fluids (2014), doi: http://dx.doi.org/10.1016/j.compfluid.2014.02.023

8. G. Pisanich and S. Morris, "Fielding an amphibious UAV: development, results, and lessons learned," in Digital Avionics Systems Conference, 2002. Proceedings. The 21st, vol. 2. IEEE, 2002, pp. 8C4-1.

9. Sethuramalingam, T. K., and B. Nagaraj. "A soft computing approach on ship trajectory control for marine applications." ARPN J Eng Appl Sci 10, no. 9 (2015): 4281-4286.

10. R. D. Eubank, "Autonomous flight, fault, and energy management of the flying fish solar-powered seaplane," Ph.D. dissertation, The University of Michigan, 2012.

11. R. Siddall and M. Kovac, "Launching the aquamav: bioinspired design for aerial-aquatic robotic platforms," Bioinspiration \& biomimetics, vol. 9, no. 3, p. 031001 , 2014.

12. M. Schwarzbach, M. Laiacker, M. Mulero-P'azm'any, and K. Kondak, "Remote water sampling using flying robots," in Unmanned Aircraft Systems (ICUAS), 2014 International Conference. IEEE, pp. 72-76.

13. P. L. Drews, A. A. Neto, and M. F. Campos, "Hybrid unmanned aerial underwater vehicle: Modeling and simulation," in 2014 IEEE/RSJ International Conf. on Intelligent Robots and Systems, pp. 4637-4642.

14. J.-P. Ore, S. Elbaum, A. Burgin, and C. Detweiler, "Autonomous aerial water sampling," J. of F. Robotics, vol. 32, no. 8, pp. 1095-1113, 2015.

15. X. Yang, J. Liang, T.Wang, G. Yao, W. Zhao, and Q. Shen, "Submersible unmanned aerial vehicle concept design study," in 2013 Aviation Technology, Integration, and Operations Conference, p. 442. 